\title{
How Valid Are Self-Reports of Illness-Related Absence? Evidence from a University Employee Health Management Program
}

\author{
Kristi Rahrig Jenkins, $\mathrm{PhD}^{1}$
}

\begin{abstract}
The present study uses a focused approach to compare self-reported versus administratively recorded measures of absences related to health or illness. To date, the few studies that focus on this topic produced mixed results. To help shed light on this issue, the present research has 2 related objectives: (1) examine how highly correlated self-reported and administratively recorded measures of absences related to health or illness might be, and (2) how each measure predicts various aspects of health. Using data from the 2012 StayWell ${ }^{\circledR}$ Health Management health risk appraisal (HRA) and 1 year (2011) of administratively recorded timekeeping data, bivariate analyses for continuous variables and generalized linear modeling for variables with greater than 2 response categories were used. For the multivariate analyses, linear regression models controlling for sex, age, race, income, job status, and campus location were calculated for the continuous outcomes (ie, self-rated health and chronic conditions). Results indicate that self-reported and administratively recorded absences related to health or illness were moderately correlated (correlation coefficient of 0.47 ). In addition, each measure functioned similarly (in direction and magnitude) to predict health outcomes. Both greater self-reported and recorded illness-related absenteeism was associated with poorer self-rated health and greater numbers of chronic conditions. These results suggest that self-rated illness-related absenteeism may be a reasonable way to assess various program outcomes meaningful to employers, particularly if administratively recorded measures are unavailable or too time consuming or expensive to analyze. (Population Health Management 2014;17:211-217)
\end{abstract}

\section{Background}

A SIDE FROM THE PERSONAL TOLL, absenteeism related to health and illness also can be a significantly costly problem for employers. ${ }^{1}$ A study conducted by Gallup surveyed over 100,000 full-time workers in the United States and estimated productivity losses at over $\$ 153$ billion annually for employees who were above normal weight and have 1 or more chronic conditions. ${ }^{2}$ Absenteeism from work related to illness may contribute to decreases in productivity, 3,4 employee morale, ${ }^{5}$ and in general to a less efficient workplace. ${ }^{6}$ A better understanding of the functionality of different ways of assessing absenteeism (eg, company timekeeping records vs. self-reported assessments) and how those different assessments predict various health outcomes is important for research and evaluation of programs that focus on population health management.

Because of the availability and relative ease of use compared to administratively recorded absenteeism data, self-reported data on illness-related absenteeism is com- monly used to assess the association of absenteeism with health risks, health care costs, and health conditions. ${ }^{7}$ Even though self-reported measures are of value to employers, little work has assessed the agreement between administratively recorded and self-reported absenteeism (with some exceptions $\left.{ }^{7,8,9}\right)$. This is a problem in workplace settings where important programs are evaluated based on the assumption that the agreement between self-reported and administrative records of illness-related absenteeism is moderate to high.

The little work that has focused on the agreement between self-reported versus administratively recorded measures of illness-related absenteeism has produced mixed results. In a study that assessed 312 almost entirely male (99\%) cargo employees from a Dutch airline, Poppel et al found that self-reported and administratively recorded measures of illness-related absenteeism have a low level of agreement. ${ }^{8}$ Others found that employees tend to underestimate their self-reported illness-related absent days compared to those administratively recorded measures. ${ }^{10}$ In

MHealthy, University of Michigan Health and Wellbeing Services, Ann Arbor, Michigan. 
contrast, some research finds that self-reported and administratively recorded measures of illness-related absenteeism have a strong level of agreement. ${ }^{11,12}$ More work is needed to better understand the association between these 2 measures.

When assessing the association between measures, an important component is determining how similarly each measure functions with regard to predicting relevant outcomes. One recent study by Eriksson et al examines the association of self-reported illness-related absenteeism with self-rated health and symptomatology from over 43,000 residents in 5 counties in central Sweden. They found that self-reported illness-related absenteeism was associated with poorer self-rated health and a greater number of symptoms. ${ }^{13}$ Other work found similar results. ${ }^{14,15}$ One limitation of the Ericksson et al study was the use of a selfreported measure of illness-related absenteeism rather than a recorded assessment. The present study seeks to address this limitation by reviewing how each measure (both selfreported and administratively recorded measures of absences related to health or illness) predicts self-rated health and a count of chronic conditions. Assessing how each measure functions with regard to health outcomes is important to develop a better understanding of how accurate these 2 measures are in assessing the same construct (ie, illness-related absenteeism).

The present study uses a focused approach to compare the agreement between self-reported versus administratively recorded measures of absences related to health or illness. To date, there are few studies that focus on this topic. To help shed light on this issue, the present research has 2 related objectives: (1) examine how highly correlated self-reported and administratively recorded measures of absences related to health or illness might be, and (2) how each measure predicts various aspects of health. It is hypothesized that (1) selfreported and administratively recorded measures will be moderately to highly correlated, and (2) they will predict health outcomes similarly (in direction and magnitude), with more days absent being associated with poorer self-rated health and greater numbers of chronic conditions.

\section{Methods}

\section{Data}

Data were collected annually using the StayWell ${ }^{\circledR}$ Health Management health risk appraisal (HRA). Voluntary completion of the HRA was part of an employee incentive program used to promote health and well-being at a large midwestern university. Since 2009 the university had a $\$ 100$ per year pretax incentive for its wellness program. The criteria for receiving the incentive changed somewhat throughout the years. Participants received a $\$ 100$ per year pretax incentive for: completing an HRA and a wellness screening (2009), completing an HRA and 2 eligible wellness activities (2010), completing an HRA and 1 wellness activity (2011), completing an HRA and a wellness screening (2012), and completing an HRA and 1 wellness activity (2013).

The incentive program is administered by the university's employee health management program, a comprehensive population health strategy that provides high-quality services and fosters a culture of health at the university. This employee health management program has an integrated organizational structure, including wellness and risk-reduction services, employee assistance programs, occupational health services, and more and serves the university's approximately 40,000 employees. This incentive program began in 2009 and has continued each following year.

Employees' HRAs and their administratively measured absence data are individually linked and sent on separate files to a third-party vendor for de-identification. Thus, the user of these data cannot identify specific employees-only that they are unique individuals. It is important to note that the author was granted Institutional Review Board approval for this study.

\section{Analytic sample}

The HRA response rate was $48 \%$ for $2009,42 \%$ for 2010 , $55 \%$ for $2011,54 \%$ for 2012, and $56 \%$ for 2013. In 2012 there were 20,506 benefits eligible (and who did not waive their health insurance coverage) HRA participants. There are 2 timekeeping processes at the university (ie, paid time off, sick and vacation time). Of those 20,506 benefits eligible participants, 11,766 HRA participants were excluded from these analyses because their timekeeping process did not allow one to distinguish between sick and vacation time (paid time off). This study focused on respondents who had a continuous 12 months of administratively recorded nonzero hours of sick time in 2011, completed the HRA in 2012, and had complete data on the independent variables. This reduced analytic sample to 5746 participants. When comparing race, age, and sex, the demographic characteristics of this analytic sample compared to the overall university population ${ }^{16}$ are quite similar. Across those 3 variables, the percentage point difference between the overall university and the analytic sample ranges from 0-4 percentage points.

The university also offers 2 robust long-term disability (LTD) plans. University employees who qualify for benefits under one of the LTD plans receive salary replacement and fringe benefits continuation. In order to qualify for benefits under either LTD plan, an employee must have an impairment that renders them completely unable to engage in any occupation or employment for which they are reasonably suited by education, training, or experience. The impairment must be expected to result in death or to have lasted, or be expected to last, for a continuous period of not less than 12 months from their last day of work. In 2013, approximately $2 \%$ of university employees were receiving LTD benefits. Given this, there were essentially 2 main reasons for excluding employees on LTD from these analyses: (1) there is a very small sample of employees who qualify for LTD, and (2) their nonwork status likely would skew absenteeism results.

\section{Measures}

Administratively recorded absence. The university offers employees a generous sick time benefit. Annually, on an employee's hire date, campus employees receive 15 days per year of sick time (exception time varies by union contract). Sick time days cannot be rolled over. As a result, length of employment should have little effect on these analyses. 
One year (2011) of administratively recorded timekeeping data was used for these analyses. The codes that were used to create this measure were: (1) taking sick time without pay, (2) preventive sick appointment (eg, follow-up appointment or physical exam), (3) taking sick time from vacation time, and (4) sick time related to an illness or injury. Also, one particular group of employees has a different set of timekeeping processes that do not allow one to distinguish between vacation and sick time. For this reason, their timekeeping data also were excluded from these analyses.

Self-reported absence. Self-reported illness-related absenteeism was measured with a question contained on the 2012 StayWell $^{\circledR}$ HRA: How many days did you miss from your job because of illness or injury in the last 12 months? If you don't work outside the home, how many days were you unable to do your usual activities in the last 12 months? Responses (coding in parentheses) were: None $(=0), 1$ day $(=1), 2$ days $(=2), 3$ days $(=3), 4$ days $(=4), 5$ days $(=5)$, 6 days $(=6), 7$ days $(=7), 8$ days $(=8), 9$ days $(=9), 10$ days $(=10), 11-15$ days $(=13), 16-20$ days $(=18), 21-30$ days $(=25.5)$, and 31 or more days $(=31)$. This was treated as a continuous measure of self-reported absence.

Self-rated health. Self-rated health was assessed by asking participants to rate their health in the past 4 weeks on a 6 -point scale (excellent $=0$ to very poor $=5$ ). Higher numbers represent poorer health. ${ }^{17,18,19}$ Self-rated health also is associated with other objective measures of health status including mortality. ${ }^{20}$

Self-reported chronic conditions. Chronic health conditions were measured from the HRA by obtaining a count of self-reported chronic conditions. Nineteen different conditions were listed: arthritis, osteoporosis, asthma, hay fever or other seasonal allergy, lung disease, cancer except skin, skin cancer, type 1 diabetes, type 2 diabetes, high blood pressure, high/unhealthy cholesterol, chronic heartburn, congestive heart failure, heart disease (coronary artery disease, angina, or heart attack), lower back pain, migraine or chronic severe headaches, depression, chronic insomnia, and other chronic conditions. Conditions that were checked were coded as 1 and conditions that were not checked were coded as 0 . These measures were coded similarly as in other published analyses. $^{21}$

Covariates. Because health differs by age, sex, ${ }^{22}$ income, ${ }^{23}$ race, ${ }^{24}$ and measures of occupational prestige, ${ }^{26}$ age, sex, income, race, and job type were included in the models as covariates. Age was included as a continuous variable, measured in years. Sex was coded as female $=1$ and male $=0$. Race and ethnicity were combined into the following categories: white, African American, Asian, or Hispanic $($ reference $=$ white $)$. Regarding job status, participants were asked if they held: managerial, professional/ nonmanagerial, or sales positions (each of these responses was collapsed into the category of manager); technical, clerical/office, or laborer/production positions (each of these responses was collapsed into the category of laborer); or were a homemaker/student or retiree (each of these responses was collapsed into the category of homemaker). Because of the small number of respondents in the home- maker category, these respondents were omitted from the analyses. Manager was entered in the models a separate dichotomous variable with laborer as the reference category. Faculty $=1$ and staff $=0$ status was also included. A continuous measure of respondents' annualized income also was included. The natural logarithm of income was used in the multivariate analyses to linearize the effect of the skewed distribution. For the bivariate analyses, income was coded as $<\$ 45,000$ as the reference category. The other income categories were: $\$ 45,000-\$ 75,000 ; \$ 75,001-\$ 95,000$ and $\geq \$ 95,000$. Because the social and demographic environment differs from the 4 various campuses of the university, campus location also was included as a covariate.

\section{Analysis}

The statistical package used for these analyses was SAS, release 9.1 (SAS Institute Inc., Cary, NC). The analytic sample included all respondents with complete data on the independent variables. Extreme values were excluded from these analyses. Bivariate analyses for continuous variables and generalized linear modeling for variables with more than 2 response categories were used (Table 1). For the multivariate analyses, linear regression models controlling for sex, age, race, income, job status, and campus location were calculated for the continuous outcomes (ie, self-rated health, and chronic conditions).

\section{Results}

Basic descriptive analyses were conducted to observe socioeconomic and demographic patterns between selfreported and administratively recorded illness-related absenteeism. Table 1 presents the findings of that information.

Of the 5746 respondents, for the administratively recorded measure, women tended to report higher absenteeism than men. Men had a lower discrepancy than women between recorded and self-reported absenteeism. Employees who classified themselves as a clerical, laborer, or technician had greater absences (both recorded and self-reported) and greater discrepancy between recorded and self-reported absenteeism compared to employees who classified themselves as professional or managerial. Employees who were 65 years of age and older had the highest discrepancy, while employees who were between the ages of 18-29 had the lowest discrepancy between the measures. Faculty had less discrepancy between recorded and self-reported absenteeism compared to staff. Interestingly, staff compared to faculty had higher administratively recorded days absent. There was a general linear pattern with income and absenteeism. Employees in higher income brackets had less absenteeism, regardless of the measure observed. Also, respondents in the higher income brackets had less discrepancy between recorded and self-reported absenteeism. When reviewing the patterns with campus location, one sees that campus 1 had the greatest disparity between self-reported and administratively recorded absenteeism compared to the other 3 campuses. Campus 4 had the highest number of self-reported and administratively recorded illness-related absenteeism compared to the other 3 campuses.

Table 2 reviews the results of self-reported and administratively recorded illness-related absenteeism on self-rated health. In general, both measures of illness-related absenteeism work similarly. Greater illness-related absenteeism 
Table 1. Mean and Difference Between Administratively Recorded and Self-Reported Annual Sick Days (N=5746)

\begin{tabular}{|c|c|c|c|c|c|c|}
\hline & \multirow[b]{2}{*}{$\mathrm{n}$} & \multicolumn{2}{|c|}{ Mean annual sick days } & \multirow{2}{*}{$\begin{array}{c}\text { Discrepancy } \\
\text { in number of days } \\
\text { recorded and self-reported }\end{array}$} & \multicolumn{2}{|c|}{ Significance } \\
\hline & & Recorded & Self-reported & & Recorded & Self-reported \\
\hline Sex & & & & & *** & \\
\hline Female & 4,284 & 6.12 & 4.17 & 1.95 & & \\
\hline Male & 1,462 & 5.34 & 4.04 & 1.30 & & \\
\hline Age & & & & & $*$ & $* * *$ \\
\hline $18-29$ & 789 & 5.63 & 4.48 & 1.15 & & \\
\hline $30-44$ & 2,168 & 5.89 & 4.34 & 1.55 & & \\
\hline $45-64$ & 2,688 & 6.01 & 3.87 & 2.14 & & \\
\hline$\geq 65$ & 101 & 6.68 & 3.97 & 2.71 & & \\
\hline Race/Ethnicity & & & & & & \\
\hline White & 4,752 & 5.95 & 4.15 & 1.80 & $* * *$ & \\
\hline Black American & 396 & 6.45 & 4.26 & 2.19 & & \\
\hline Latino & 178 & 5.86 & 4.14 & 1.72 & & \\
\hline Asian & 420 & 5.13 & 3.88 & 1.25 & & \\
\hline Income & & & & & **** & $* * *$ \\
\hline$<\$ 45,000$ & 2,051 & 6.34 & 4.32 & 2.02 & & \\
\hline$\$ 45,000-\$ 75,000$ & 2,643 & 6.03 & 4.18 & 1.85 & & \\
\hline$\$ 75,001-\$ 95,000$ & 629 & 5.23 & 3.82 & 1.41 & & \\
\hline$>\$ 95,000$ & 423 & 4.25 & 3.39 & 0.86 & & \\
\hline Occupational Group & & & & & $* * *$ & $*$ \\
\hline Professional/Managerial & 3,818 & 5.61 & 4.08 & 1.53 & & \\
\hline $\begin{array}{l}\text { Clerical/Laborer/ } \\
\text { Technician }\end{array}$ & 1,928 & 6.55 & 4.24 & 2.31 & & \\
\hline Faculty/Staff & & & & & $* * *$ & \\
\hline Faculty & 231 & 4.94 & 4.24 & 0.70 & & \\
\hline Staff & 5,515 & 5.96 & 4.13 & 1.83 & & \\
\hline Campus & & & & & ** & $* *$ \\
\hline Campus 1 & 79 & 6.27 & 3.56 & 2.71 & & \\
\hline Campus 2 & 5,290 & 5.87 & 4.11 & 1.76 & & \\
\hline Campus 3 & 179 & 6.42 & 4.57 & 1.85 & & \\
\hline Campus 4 & 198 & 6.75 & 4.66 & 2.09 & & \\
\hline
\end{tabular}

$* P<.05 ; * * P<.01 ; * * * P<.001$.

is associated with poorer self-rated health $(b=0.03$ for administratively recorded illness-related absenteeism versus $\mathrm{b}=0.08$ for self-reported illness-related absenteeism).

When reviewing race and ethnicity, income, and occupational group, the results also were very similar between the 2 measures. Black, Latino, and Asian reported poorer self-rated health compared to white employees. Lower income was associated with poorer self-rated health. Employees classifying themselves as clerical, laborer, or technician had poorer self-rated health compared to those employees who classified themselves as professional or managerial. Regarding age, in both models predicting selfrated health, those employees 65 years of age and older reported better self-rated health compared to those aged 18-29. This same pattern was observed for the 45-64 age group in the administratively recorded illness-related absenteeism model. In the self-reported illness-related absenteeism model, those classified as 30-44 years of age reported poorer self-rated health compared to those 18-29 years of age. Interestingly, in the administratively recorded sick days model, females reported better self-rated health compared to males.

Table 3 is structured similarly to Table 2 . Table 3 reviews the results of self-reported and administratively recorded illness-related absenteeism for a count of self-reported chronic conditions. As with self-rated health, both measures of illness-related absenteeism function similarly. Greater illness-related absenteeism is associated with a greater number of chronic conditions $(b=0.06$ for administratively recorded illness-related absenteeism versus $b=0.10$ for self-reported illness-related absenteeism).

There were no statistically significant effects in either of the 2 models with regard to income, occupational group, faculty/staff status, or campus location. However, in both models, the associations with age, sex, and race/ethnicity were very similar between the 2 measures. Being female is associated with a higher number of self-reported chronic conditions compared to being male. Across all age categories, being older is associated with a greater number of chronic conditions, compared to being 18-29 years of age. Self-reporting an Asian race (compared to white) is associated with a fewer number of chronic conditions.

\section{Discussion}

Illness-related absenteeism is associated with various outcomes that are important to employers. ${ }^{25}$ Evidence suggests 
Table 2. Estimated Regression Coefficients

FOR SELF-REPORTED AND ADMINISTRATIVELY

Recorded Sick Days on Self-Rated Health

\begin{tabular}{|c|c|c|}
\hline & $\begin{array}{c}\text { Administratively } \\
\text { Recorded Sick } \\
\text { Days on Self- } \\
\text { rated Health }\end{array}$ & $\begin{array}{c}\text { Self-reported } \\
\text { Sick Days on } \\
\text { Self-rated } \\
\text { Health }\end{array}$ \\
\hline \multicolumn{3}{|l|}{ Sex } \\
\hline Male & Ref. & Ref. \\
\hline Female & $-0.06 *$ & -0.04 \\
\hline \multicolumn{3}{|l|}{ Age } \\
\hline $18-29$ & Ref. & Ref. \\
\hline $30-44$ & 0.06 & $0.08 *$ \\
\hline $45-64$ & $-0.12 * *$ & -0.06 \\
\hline$\geq 65$ & $-0.39 * * *$ & $-0.32 * * *$ \\
\hline \multicolumn{3}{|l|}{ Race/Ethnicity } \\
\hline White & Ref. & Ref. \\
\hline Black American & $0.17 * * *$ & $0.18 * * *$ \\
\hline Latino & $0.19 * *$ & $0.19 * *$ \\
\hline Asian & $0.24 * * *$ & $0.24 * * *$ \\
\hline Income & $-0.17 * * *$ & $-0.16^{* * *}$ \\
\hline \multicolumn{3}{|l|}{ Occupational Group } \\
\hline Professional/Managerial & Ref. & Ref. \\
\hline Clerical/Labor/Technician & $0.10 * * *$ & $0.12 * * *$ \\
\hline \multicolumn{3}{|l|}{ Faculty/Staff } \\
\hline Staff & Ref. & Ref. \\
\hline Faculty & -0.01 & -0.05 \\
\hline \multicolumn{3}{|l|}{ Campus } \\
\hline Campus 2 & Ref. & $\mathrm{N} / \mathrm{A}$ \\
\hline Campus 1 & -0.10 & -0.04 \\
\hline Campus 3 & -0.08 & -0.11 \\
\hline Campus 4 & 0.04 & 0.03 \\
\hline Recorded Sick Days & $0.03 * * *$ & N/A \\
\hline Self-reported Sick Days & N/A & $0.08 * * *$ \\
\hline
\end{tabular}

$* P<.05 ; * * P<.01 ; * * * P<.001$.

that greater illness-related absenteeism is associated with poorer self-rated health, ${ }^{14}$ a greater number of medical claims, ${ }^{27}$ and lower productivity. ${ }^{28}$ Such studies typically measure absenteeism via self-report from surveys. Yet, with the exception of a few studies, ${ }^{29,30}$ little research has focused on the validity of administratively recorded illnessrelated absenteeism as compared to self-reported illnessrelated absenteeism. Given that illness-related absenteeism is meaningful for research and evaluation that influences key decisions among stakeholders, this study sought to address this important gap in the literature.

Results from this study provide some support for both of the hypotheses. First, self-reported and administratively recorded measures of absences related to health or illness were moderately correlated. The correlation between the 2 measures was statistically significant and had a correlation coefficient of 0.47 . In addition, holding constant a number of important social and demographic factors, each measure functioned similarly (in direction and magnitude) to predict health outcomes. Both greater self-reported and measured illness-related absenteeism was associated with poorer selfrated health and greater numbers of chronic conditions.

More specifically, this study showed that employees tend to underestimate their self-reported illness-related absent days compared to those administratively recorded measures. This
Table 3. Estimated Regression CoefFicients FOR SELF-REPORTED AND ADMINISTRATIVELY RECORDED Sick Days on Self-Reported Chronic Conditions

\begin{tabular}{|c|c|c|}
\hline & $\begin{array}{c}\text { Administratively } \\
\text { Recorded Sick } \\
\text { Days on Chronic } \\
\text { Conditions }\end{array}$ & $\begin{array}{l}\text { Self-reported } \\
\text { Sick Days } \\
\text { on Chronic } \\
\text { Conditions }\end{array}$ \\
\hline \multicolumn{3}{|l|}{ Sex } \\
\hline Male & Ref. & Ref. \\
\hline Female & $0.12 * *$ & $0.15 * * *$ \\
\hline \multicolumn{3}{|l|}{ Age } \\
\hline $18-29$ & Ref. & Ref. \\
\hline $30-44$ & $0.35 * * *$ & $0.38 * * *$ \\
\hline $45-64$ & $0.95 * * *$ & $1.04 * * *$ \\
\hline $65-80+$ & $1.64 * * *$ & $1.76 * * *$ \\
\hline \multicolumn{3}{|l|}{ Race/Ethnicity } \\
\hline White & Ref. & Ref. \\
\hline Black American & -0.13 & -0.11 \\
\hline Latino & -0.06 & -0.05 \\
\hline Asian & $-0.59 * * *$ & $-0.60 * * *$ \\
\hline Income & -0.10 & -0.10 \\
\hline \multicolumn{3}{|l|}{ Occupational Group } \\
\hline Professional/Managerial & Ref. & Ref. \\
\hline $\begin{array}{l}\text { Clerical/Labor/ } \\
\text { Technician }\end{array}$ & -0.02 & 0.02 \\
\hline \multicolumn{3}{|l|}{ Faculty/Staff } \\
\hline Staff & Ref. & Ref. \\
\hline Faculty & 0.12 & 0.06 \\
\hline \multicolumn{3}{|l|}{ Campus } \\
\hline Campus 2 & Ref. & N/A \\
\hline Campus 1 & -0.14 & -0.05 \\
\hline Campus 3 & -0.07 & -0.09 \\
\hline Campus 4 & 0.01 & 0.01 \\
\hline Recorded Sick Days & $0.06 * * *$ & N/A \\
\hline Self-reported Sick Days & N/A & $0.10 * * *$ \\
\hline
\end{tabular}

$* P<.05 ; * * P<.01 ; * * * P<.001$.

is consistent with previous research. ${ }^{10}$ This underestimation may be attributable in part to the 12-month recall period, which has been suggested to provide less accurate responses compared to shorter recall periods. ${ }^{7}$ Employers might consider selecting a survey that utilizes a self-reported measure of illness-related absenteeism that has a shorter recall period.

In addition, this study finds strong similarities in the functionality of self-reported and administratively recorded measures of illness-related absenteeism with self-rated health and number of self-reported chronic conditions. Other studies that have explored related outcomes such as allcause mortality $^{31}$ and health risks ${ }^{32}$ have found similar associations. This, in turn, stresses the importance of reviewing the agreement between these 2 measures to ensure that programming and business decisions based on evidence resulting from self-reported absenteeism data are accurate.

These results suggest that self-reported absenteeism was only moderately correlated with administratively recorded absenteeism. However, that factor, along with the similar predictive nature of the 2 measures, may suggest that selfrated illness-related absenteeism is a reasonable proxy for administratively recorded measures of illness-related absenteeism. This may be so particularly when administratively recorded measures are not available or are too time consuming to analyze. To strengthen this argument, future 
work may want to consider other health outcomes, different recall periods of self-reported absenteeism, and longitudinal measures of absenteeism when exploring this association.

These results should be interpreted in the context of several potential limitations of the study. First, the measure of self-reported illness-related absenteeism is based on a 12month recall. Studies suggest that shorter (eg, 1 month) versus longer (eg, 1 year) recall periods are less prone to recall biases and in turn produce more accurate responses. Employers might place a preference on surveys with shorter recall periods for the self-reported measures. Second, the timing of both the self-reported and administratively recorded measures of illness-related absenteeism may contribute in part to the moderate correlation between the 2 measures. The self-reported measure asks respondents to report their illness days within the prior 12 months. Respondents could have taken the survey anytime from January-April 2012. The administratively recorded measure utilized data collected from calendar year 2011. The slight difference in time frame may have contributed to the underreporting of the self-reported measure. Third, given the university's generous sick time benefit, it is possible that some employees may take advantage of this generous benefit and use more sick time than is strictly necessary. This could have at least 1 possible effect on these results; some employees' self-reported sick time may be a more precise measure of actual illness (ie, lower average number of days) rather than simply time off work. In turn, this could contribute to the moderate, rather than high, correlation between the self-reported versus administratively measured illness-related absenteeism. Fourth, the data collection process of administrative timekeeping data varies from university unit to university unit. Web clocks, time clocks, and employee self-service time sheets are the typical collection methods employed. Generally, employees enter their own timekeeping data using these tools and their manager provides approval status of the employee's entry. The non-salaried employees (referred to by the university as nonexempt employees) report their time to the nearest 10th of an hour. Salaried employees (referred to by the university as exempt employees) report their exception time in half-day increments. Thus, it is plausible that nonexempt employees have more precise administratively recorded illness-related absenteeism than exempt employees.

The interpretation and resultant implications of these findings are important for employers, researchers, and program evaluators. These results suggest that self-rated illnessrelated absenteeism may be a reasonable way to assess various program outcomes that are meaningful to employers. Assessing the agreement between other selfreported and administratively recorded measures such as health care utilization, particularly over time, also may be important in making business analytics more efficient.

\section{Author Disclosure Statement}

Dr. Jenkins declared no conflicts of interest with respect to the research, authorship, and/or publication of this article. The author received no financial support this article.

\section{Acknowledgments}

The author would like to thank Nour Fakhoury, MA for her editorial assistance.

\section{References}

1. Wright DW, Beard MJ, Edington DW. Association of health risks with the cost of time away from work. J Occup Environ Med 2002;44:1126-1134.

2. Witters D, Agrawal S. Unhealthy U.S. workers' absenteeism costs $\$ 153$ billion. <http://www.gallup.com/poll/ 150026/Unhealthy-Workers-Absenteeism-Costs-153-Billion .aspx?utm_source $=$ tagrss\&utm_medium $=$ rss\&utm_campaign $=$ syndication >. Accessed August 15, 2013.

3. Silberman R. Workplace wellness programs: proven strategy or false positive? Michigan Journal of Public Affairs 2007;4:1-8.

4. Josias BA. The relationship between job satisfaction and absenteeism in a selected field services sections within an electricity utility in the Western Cape. [Dissertation]. $<$ http://verfroller.nl/rio.pdf > . Accessed August 1, 2013.

5. Circadian. Absenteeism: the bottom-line killer. < http://www .circadian.com/images/pdf/CIRCADIAN_-_Absenteeism__Bottom_Line_Killer.pdf >. Accessed August 15, 2013.

6. Smith DC. The 6-month effect on absenteeism and cost savings from workplace pedometer-based intervention: US model. Available at: < https://gccmirror.blob.core .windows.net/research/us-absenteeism.pdf $>$. Accessed August 21, 2013.

7. Short ME, Goetzel RZ, Pei X, et al. How accurate are selfreports? Analysis of self-reported health care utilization and absence when compared with administrative data. J Occup Environ Med 2009;51:786-796.

8. Van Poppel MN, de Vet HC, Koes BW, Smid T, Bouter LM. Measuring sick leave: a comparison of self-reported data on sick leave data from company records. Occup Med (Lond) 2002;52:485-490.

9. Ferrie JE, Kivimäki, Head J, Shipley MJ, Vahtera J, Marmot MG. A comparison of self-reported sickness absence with absences recorded in employers' registers: evidence from the Whitehall II study. Occup Environ Med 2005;62:74-79.

10. Kessler RC, Barber C, Beck A, et al. The World Health Organization health and work performance questionnaire (HPQ). J Occup Environ Med 2003;45:156-174.

11. Revicki DA, Brown RE, Henry DH, McNeill MV, Rios A, Watson T. Recombinant human erythropoietin and healthrelated quality of life of AIDS patients with anemia. J Acquir Immune Defic Syndr 1994;7:474-484.

12. Rees D, Cooper CL. Research note: reliability of self-report sickness absence data in the health service. Health Serv Manage Res 1993;6:140-141.

13. Eriksson HG, von Celsing AS, Wahlström R, Janson L, Zander V, Wallman T. Sickness absence and self-reported health a population-based study of 43,600 individuals in central Sweden. BMC Pub Health 2008;8:426-413.

14. Kivimäki M, Head J, Ferrie JE, Shipley MJ, Vahtera J, Marmot MG. Sickness absence as a global measure of health: evidence from mortality in the Whitehall II prospective cohort study. BMJ 2003;327:364-364.

15. Beck A, Crain AL, Solberg LI, et al. Severity of depression and magnitude of productivity loss. Ann Fam Med.2011;9: 305-311.

16. Thomas L, Palmer T. University of Michigan. Human capital report highlights-2013. Available at: < http://hr. 1 umich.edu/humancapital/2013\%20HCR\%20summary\% 20presentation.pdf > . Accessed September 24, 2013.

17. Freyer-Adam J, Gaertner B, Tobschall S, John U. Health risk factors and self-rated health among job-seekers. BMC Pub Health 2011;11:659-669. 
18. Mikolayczyk RT, Brzoska P, Maier C, et al. Factors associated with self-rated health status in university students: a cross-sectional study in three European countries. $\underline{B M C}$ Pub Health 2008;8:215.

19. Zheng H, Thomas PA. Marital status, self-rated health, and mortality: overestimation of health or diminishing protection of marriage? J Health Soc Behav 2013;54:128-143.

20. Idler $\mathrm{E}$, Leventhal $\mathrm{H}$, McLaughlin L, Leventhal E. In sickness but not in health: self-ratings, identity, and mortality. J Health Soc Behav 2004;45:336-356.

21. Garcia-Altés A, Pinilla J, Ortún V. The evolution of health status and chronic conditions in Catalonia, 19942006: the paradox of health revisited using the blinderOaxaca decomposition. BMC Health Serv Res 2011; 11:116.

22. Philips SP. Defining and measuring gender: a social determinant of health whose time has come. Int J Equity Health 2005;4:11.

23. Marmot M. The influence of income on health: views of an epidemiologist. Health Affairs (Millwood) 2002;21: 31-46.

24. Egede LE. Race, ethnicity, culture and disparities in health care. J Gen Intern Med 2006;21:667-669.

25. Yen LT, Edington DW, Witting P. Prediction of prospective medical claims and absenteeism costs for 1284 hourly workers from a manufacturing company. J Occup Med 1992;34:428-435.

26. Fujishirto K, Xu J, Fang G. What does "occupation" represent as an indicator of socioeconomic status?: exploring occupational prestige and health. Soc Sci Med 2010;71: 2100-2107.
27. Goetzel RZ, Carls GS, Wang S, et al. The relationship between modifiable health risk factors and medical expenditures, absenteeism, short-term disability, and presenteeism among employees at novartis. J Occup Environ Med 2009;51:487-499.

28. Mattke S, Balakrishnan A, Bergamo G, Newberry SJ. A review of methods to measure health-related productivity loss. Am J Manag Care 2007;13:211-217.

29. Mueller CW, Wakefield DS, Price JL, Curry JP, McCloskey JC. A note on the validity of self-reports of absenteeism. Human Relations 1987;40:117-123.

30. Kim SW. The relationship between records-based and selfreported measures of absenteeism. Kor Soc Sci J 2004;1: 167-187.

31. Vahtera J, Pentti J, Kivimaki M. Sickness absence as a predictor of mortality among male and female employees. J Epidemiol Community Health 2004;58:321-326.

32. Adams T, Cowen VS. Health risk factors and absenteeism among university employees. Am J Health Studies 2004; 19:129-137.

Address correspondence to:

Kristi Rahrig Jenkins, PhD

MHealthy, University of Michigan Health and Wellbeing Services 2060 Wolverine Tower 3003 South State St. Ann Arbor, MI, 48109

E-mail: kristirj@umich.edu 
This article has been cited by:

1. Stefan B. Gingerich, Erin L. D. Seaverson, David R. Anderson. 2017. Association Between Sleep and Productivity Loss Among 598676 Employees From Multiple Industries. American Journal of Health Promotion 089011711772251. [Crossref]

2. Jessica Grossmeier, David J. Mangen, Paul E. Terry, Laura Haglund-Howieson. 2015. Health Risk Change as a Predictor of Productivity Change. Journal of Occupational and Environmental Medicine 57:4, 347-354. [Crossref] 